\title{
Assessment of the relationship between body mass index (BMI) and dental age
}

\author{
Maryam Zangouei-Booshehri ${ }^{1}$, Fatemeh Ezoddini-Ardakani ${ }^{{ }^{*}}$, Hosein Agha Aghili ${ }^{2}$, \\ Akbar Sharifi ${ }^{3}$ \\ ${ }^{1}$ Department of Oral and Maxillofacial Radiology, Faculty of Dentistry, Shahid Sadoughi University of Medical Sciences, Yazd, Iran; \\ *Corresponding Author: ezoddini@gmail.com \\ ${ }^{2}$ Department of Orthodontics, Faculty of Dentistry, Shahid Sadoughi University of Medical Sciences, Yazd, Iran; \\ ${ }^{3}$ Faculty of Dentistry, Shahid Sadoughi University of Medical Sciences, Yazd, Iran.
}

Received 29 March 2011; revised 21 April 2011; accepted 27 April 2011.

\begin{abstract}
The aim of the study was to determine the relationship between Body Mass Index (BMI) and accelerated dental development. The dental developmental ages of 100 children aged between 8 and 12 years were determined using the Demirjian method and panoramic radiographs. BMI status was determined for each subject on the basis of the system developed by the International Obesity Task Force. There was a significant direct relationship between dental development and BMI $(P<0.01)$. Obese children have a higher rate of dental development compared to normal children. CLINICAL RELEVANCE: This is an important variable to be considered when planning for dental and orthodontic treatments in obese children. Brief objectives statement: Overweight or obesity can accelerate dental development. Accelerated dental development in overweight children is important to be considered in pediatric dentistry and orthodontics.
\end{abstract}

Keywords: Dental Age; Body Mass Index (BMI); Bone Age; Overweight

\section{INTRODUCTION}

Knowledge of the potential growth of a patient is one of the important tools for successful orthodontic and orthopedic treatments and such variables as chronological age, sexual maturity, skeletal growth stages, dental developmental stages, height and weight have been used to study the various stages of growth [1], although the relationship between height, weight and sexual maturity has not been confirmed yet [2].
If there is a strong correlation between skeletal maturity and dental calcification stages, these stages can be used as a diagnostic tool for estimating the starting point of growth. Determination of the patient's age is also very important in forensic medicine in criminals or those without recorded birth certificates both above and below 18 years old [3].

Considering the increased prevalence of obesity, there is a need for information about its possible effect on dental development as a part of epidemiological studies [4].

Body Mass Index (BMI) is a reliable index of overweight and obesity in most children and adolescents. Obesity in children can lead to skeletal problems in the head and neck region. BMI is dependent on age and gender in children and adolescents and is generally referred to as specific for a certain age [5]. Percentage range of less than $5 \%$ is considered as underweight, $5 \%$ 85\% normal, 85\% - 95\% overweight and more than 95\% is overweight. Alteration in the order of teeth eruption denotes a disorder in normal development of the teeth, rather than delayed or accelerated growth. The more time deviation of teeth eruption from normal, the more possible the presence of a problem in development of teeth [6].

Panoramic radiographs of developing teeth are used in various scientific fields for exact assessment of dental age in order to evaluate maturity and age. In clinical dentistry, dental age information is used for diagnosis and planning for treatment. In situations where there is insufficient information about the identity of the individual or correct birth date, dental age can be used to determine the age of the individual.

Radiological evaluation of the dental age in children is important for the dentist in order to have a better understanding of the dental development. Sometimes when the exact birth date of the individual is not known, his (her) 
somatic maturity rate is used to evaluate the chronological age, but as there is little difference between the dental and chronological age, the evaluation of the rate of teeth development and formation is more accurate for determining the historical age than the somatic maturity [7].

Prabhakaran N. reported that teeth are the most stable structures in the human body and their developmental pattern can be used as a reliable technique for estimating the age of unidentifiable corpses. In this study, dental age was estimated using various stages of dental development based on literature. Radiographic images depicting various stages of dental growth could be used for estimating the chronological age [8].

In studies performed in the fifth and sixth decades of the last century, there was a weak relationship between age of erupted teeth and skeletal age. Therefore researches concentrated on the calcification stages of the teeth [9].

Hilgers and coworkers studied the relationship between obesity and dental development in children. In this study 104 children were evaluated by the Demirjian method. The body mass index was normal in 63 cases, and 23 and 18 subjects were overweight and obese, respectively. They showed that dental development significantly accelerates with increase in body mass index [10].

Sadeghianrizi studied the relationship between craniofacial development and obesity. In this study, 50 lateral cephalometries were compared and it was reported that the rate of growth, development and length of craniofacial structures was more in obese individuals. They also stated that orthodontic treatment in these cases needs special considerations as their development and growth speed is more than normal individuals [11].

In the present study, the authors decided to study whether the increase in BMI is related to acceleration in teeth eruption or not.

\section{MATERIALS AND METHODS}

This was a descriptive-analytical study performed by a cross-sectional method. Children referred to the dental college of Yazd who needed panoramic radiography for dentistry treatment entered the study and the developmental state of their teeth (dental age) were evaluated. Dental age was determined using radiographic images and developmental stage of the roots. BMI was measured by dividing the height by the square of the weight. The difference between the chronological age and dental age was determined for each sex and in relation to BMI. A total of 100 children aged between 8 - 12 years were selected by simple sampling method. After obtaining the radiographic images, their height and weight was meas- ured according to the metric standards. Then BMI was calculated and compared with the respective age and gender charts.

According to the international BMI standards, children with BMI below 5\% of standard were considered as thin or underweight, between $5 \%$ - $85 \%$ as normal and above $85 \%$ as obese. As the number of samples below $5 \%$ of standard was few (only 2 cases), they were included in the normal group.

The panoramic radiographic images were taken by a SE 00810 Planmeca 2002 EC praline machine (Helsinki, finland). On the basis of Demirjian standard [6], dental development is related to root development and teeth eruption according to a known process (Table 1). Dental age was determined for each case as a single digit number. Data was segregated on the basis of gender with dental age of each specimen, chronological age and BMI of each individual. SPSS was used for analysis and statistical tests included t test and regression analysis. Level of significance was set at 0.05 .

\section{RESULTS}

One hundred children entered the study (30 boys and 70 girls). After obtaining panoramic radiographic images and evaluating the root ends and rate of calcification, the mean ( \pm standard deviation) eruption age in boys and girls was $9.796 \pm 1.88$ and $9.514 \pm 1.55$, respectively (Table 1).

In the next stage, Body Mass Index (BMI) of the children was calculated and they were divided into two groups: normal and above normal. 85\% of children were in the normal group and 15\% were in the above normal group (Table 2). The mean eruption age was evaluated separately in each group (Table 3). The minimum and maximum dental age on the basis of BMI is depicted in Table 4.

At the end, in order to evaluate the effect of BMI on eruption age, the difference in mean BMI of various groups was studied. There was a statistically significant difference between the mean BMI of two groups ( $P$ value $=0.41$.

\subsection{Coefficient Ratio between Variables}

In order to study the effect of various variables on growth, coefficient ratio between various variables was evaluated (Table 5).

\section{DISCUSSION}

The present study was performed to study the relationship between dental age and BMI in 8 - 12 year-old children. Panoramic radiographic images were used to determine the dental age. 
Table 1. Distribution of children on the basis of gender and mean eruption age in each group.

\begin{tabular}{ccccc}
\hline Gender & Number & $\begin{array}{c}\text { Mean } \\
\text { Chronological } \\
\text { Age }\end{array}$ & $\begin{array}{c}\text { Mean Eruption } \\
\text { Age }\end{array}$ & $\begin{array}{c}\text { Standard } \\
\text { deviation }\end{array}$ \\
\hline Boys & 30 & 10.6 & 9.8 & 1.88 \\
Girls & 70 & 9.5 & 9.6 & 1.55 \\
\hline
\end{tabular}

$\mathrm{T}=1.039 ;$ P value $=0.488$.

Table 2. Distribution of the percentage of children on the basis of BMI.

\begin{tabular}{lcc}
\hline & Number & Percentage \\
\hline Normal & 85 & $85 \%$ \\
Above Normal & 15 & $15 \%$ \\
Total & 100 & $100 \%$ \\
\hline
\end{tabular}

Table 3. Mean eruption age on the basis of normal and above normal BMI.

\begin{tabular}{lccc}
\hline \multicolumn{1}{c}{ BMI } & Distribution & $\begin{array}{c}\text { Mean Eruption } \\
\text { Age }\end{array}$ & $\begin{array}{c}\text { Standard } \\
\text { Deviation }\end{array}$ \\
\hline $\begin{array}{l}\text { Normal } \\
\begin{array}{l}\text { Above Nor- } \\
\text { mal }\end{array}\end{array}$ & 85 & 9.5 & 1.7 \\
\hline
\end{tabular}

$\mathrm{T}=1.309 ; \mathrm{P}$ value $=0.301$.

Table 4. Minimum and maximum dental age on the basis of BMI.

\begin{tabular}{lcc}
\hline \multicolumn{1}{c}{ BMI } & Minimum Dental Age & Maximum Dental Age \\
\hline Normal & 6 & 13 \\
Above Normal & 12 & 13 \\
\hline
\end{tabular}

Table 5. Coefficient ratio between various variables.

\begin{tabular}{ccccc}
\hline & Dental age & Height & Weight & $\begin{array}{c}\text { Body Mass } \\
\text { Index (BMI) }\end{array}$ \\
\hline $\begin{array}{c}\text { Coefficient } \\
\text { Ratio }\end{array}$ & 1 & 0.509 & 0.436 & 0.047 \\
\hline
\end{tabular}

Nathile and coworkers stated that awareness about the growth potential of a patient is one of the important tools for successful orthodontic and orthopedic treatment and such parameters as chronological age, gender, stages of skeletal growth, stages of dental development height and weight are used to measure stages of growth [1]. In another study by Solhem and coworkers, it was stated that significant and relatively major differences are present among children with same chronological age and therefore the physiological and biological ages need to be studied. Physiological age is the speed of progress to- ward the maturity and can be determined by dental, skeletal and sexual maturity. Annul increase in height and weight is the index of physical body maturity.

Nathalie Bosmans and coworkers reported that the use of panoramic radiographic images is useful for evaluating dental age and there isn't any significant difference between this method and peri-apical and other radiographic techniques [12]. Suhalze and coworkers evaluated the accuracy of panoramic radiographic images and concluded that horizontal measurements are more reliable than vertical ones [13]. Solheim and coworkers showed that radiographic techniques which estimate the dental age based on dental morphology are the best techniques [14]. In the present study, panoramic radiographic images were used to estimate the dental age and BMI of the children under study was also determined. Evelyn P stated that the obesity in children and adults is associated with some complications and the rate of obesity has doubled in the last 25 years [13]. Similarly, studies have shown that obesity can affect various systems and bones of the body $[15,16]$. Considering the increase in rate of obesity in children with its associated skeletal and dental complications, the effect of BMI on dental age was studied in the present study.

Gbstein and coworkers studied the effects of gender on obesity in children. Obese children usually have less physical activity which is more prominent in girls and becomes more apparent with increasing age [17]. As a result, obesity and increased BMI result in more complications, one of which can be alterations in skeletal and developmental growth. In the present study, there was a stronger coefficient ratio between increased BMI in boys and increased eruption of teeth. The difference can be related to genetic factors and difference in diet between Iranian and European children. The present study included 100 children (30 boys and 70 girls) with a mean eruption age of 9.766 in boys and 9.514 in girls, from which, 85\% had normal Body Mass Indices and 15\% had above normal BMI. In Evelyn P study, there was a double rate of obesity and increased incidence of high BMI was reported [18].

In the normal BMI group, the mean eruptive age was $9.5176 \pm 1.63745$, while in the above normal BMI group, it was 10.00 which shows that increased BMI results in increased eruptive age. In the study by Sudeghrianrizr and coworkers, it was shown that genetic control is responsible for $1 / 3$ of the changes in BMI. In obese individuals, there is a significant reduction in secretion of growth hormone and as a result, changes in growth hormone secretion can affect the growth of the facial skeleton. The radiographic images of obese individuals were compared with that of normal individuals and results showed that there were significant differences between 
sexes. They also concluded that these growth changes due to obesity require that alterations be made in dentistry treatment plans, especially orthodontic treatments [11].

Hilgers K. K. studied the effect of children obesity on dental development and concluded that children with increase in weight and/or increase in BMI have increased dental development even if they are evaluated in relation to the age and sex of the child. This increased dental development is considered as an important variable in pediatric dentistry and orthodontic treatment [16].

The present study showed that there is a high level of relationship between chronological and dental age $(r=$ 0.784). Similarly, there was inverse relationship between height and BMI $(r=1.21)$. Akinbami and coworkers studied the role of BMI, mandibular bone and dental mandibular angle in impaction of the third mandibular molar teeth. Two factors determining the impaction were length of the mandible and difference between length of the alveolar angle and the total measurement of the teeth. The BMI of each case was measured and it was reported that prediction of the third mandibular molar teeth impaction depends upon two factors: length of the mandible and difference between the length of the arch and total dental measurement [19].

Tureli and coworkers studied the relationship between state of mastication and dental changes and BMI in 97 children aged 8 - 12 years old. The dental state, BMI and socio-economical status of the population under study were evaluated and they concluded that children with normal weight have better mastication compared to children with above normal BMI. State of weak mastication had a significant relationship with decrease in weight and position of the permanent teeth in children with normal weight [20].

Sanchez-Perez L. et al. studied the possible association between dental caries, and body mass index (BMI) and the effect of BMI on tooth eruption in a cohort of elementary school children. They concluded that the obese children had more erupted teeth and a lower caries index. The relationship of body composition and oral health should be considered in pediatric patients [21].

\section{ACKNOWLEDGEMENTS}

Overweight or obese can accelerate dental development. Accelerated dental development in overweight children is important to be considered in pediatric dentistry and orthodontics.

\section{REFERENCES}

[1] Demirjan, A., Buschang, R., Tanguay, R. and Patterson, K. (1985) Inter relationship among measure of somatic, skeletal, dental and sexual maturity. American Journal of Orthodontics, 88, 433.

doi:10.1016/0002-9416(85)90070-3

[2] Grave, K.C. and Brown, T. (1976) Skeletal maturation and adolescent growth spurt. American Journal of Orthodontics, 69, 611-620. doi:10.1016/0002-9416(76)90143-3

[3] Bang, G. and Ramm, E. (1970) Determination of age in humans from root dentin transparency. Acta Odontologica Scandinavica, 28, 3-35. doi:10.3109/00016357009033130

[4] Flegul, K.M. (1999) The obesity epidemic in children and adults: current evidence and research issues. Medicine \& Science in Sports \& Exercise, 31, 509-514. doi:10.1097/00005768-199911001-00004

[5] Grummer-Strawn, M.Z. L.M, Pietrobelli, A., Goulding, A., et al. (2002) Validity of body mass index compared with other body composition screening indexed for the assessment of body fitness in children and adolescents. American Journal of Clinical Nutrition, 75, 978-985.

[6] Profit, W.R. and Fields, H.W. (2000) Contemporary orthodontics. 3rd Edition, Mosby Year Book, St Louis.

[7] Lewis, A.B. and Garn, S.M. (1960) The relationship between tooth formation and other maturational factors. The Angle Orthodontist, 30, 70-77.

[8] Phrabhakaran, N. (1995) Age estimation using third molar development. Malaysian Journal of Pathology, 17, 31-34.

[9] Avery, D.R. and Macdonald, E.M. (2000) Pediatric dentistry for the child and adolescent. 7th Edition, Mosby Year Book, St Louis.

[10] Hilgers, K.K. and Kinane, D.E. (2006) Association between childhood obesity and dental development. Pediatric Dentistry, 28, 23-28.

[11] Sadeghrianrizi, A., Forsberg, C.M., et al. (2006) Obesity appeared associated with more pronounced prognathisms and greater facial dimensions. Craniofacial Development in Obese Adolescents, 70-80.

[12] Nathile, B., Peirs, A., Medhet, A. and Gwy, W. (2006) The application of kvaal's dental age calculation technique on panoramic dental radiographs. Forensic Science International, 153, 208-212.

[13] Schulze, R., Krummenauer, F. and Schallduch, F. (2000) Precision and accuracy of measurements in drgitol panoramic radiography. Dentomaxillofacial Radiology, 29, 52-56. doi:10.1038/sj.dmfr.4600500

[14] Solheim, T. (1993) A new method for dental age estimation in adults. Forensic Science International, 59, 137147. doi:10.1016/0379-0738(93)90152-Z

[15] Lobstein, T., Baur, L. and Uallu, R. (2004) Obesity in children and young people: A crisis in public health. Obesity Reviews, 5, 4-85. doi:10.1111/j.1467-789X.2004.00133.x

[16] Hilgers, K.K., Axridge, M., Scheetz, J.P. and Kinane, D.E. (2006) Childhood obesity and dental development. Pediatric Dentistry, 18, 16-22.

[17] Leonard, H. and Epitein, R.A. (2001) Sex differences in obese children and sibling in family-based obesity treatment. Obesity Research, 9, 746-753. doi:10.1038/oby.2001.103

[18] Evalgn, P., Selvi, B., Rachel, G. and Paula, R.S. (2005) Screening and Interventions for childhood over weight. 
Journal of Pediatrics, 116, 502-529.

[19] Akinbami, B.O. and Didia, B.C. (2010) Analysis of body mass index, the mandible, and dental alveolar arch factors in prediction of mandibular third molar impaction: A pilot study. Journal of Contemporary Dental Practice, 11, 41-48.

[20] Tureli, M.C., Barbosa, T. and Gaviao, M.B. (2010) Asso- ciations of masticatory performance with body and dental variables in children. Pediatr Dent, 32, 283-288.

[21] Sanchez-Perez, L., Irigoyen, M.E. and Zepda, M. (2010) Dental caries, tooth eruption timing and obesity: A longitudinal study in a group of Mexican schoolchildren. Acta Odontologica Scandinavica, 68, 57-64. doi:10.3109/00016350903449367 